\title{
Assessment of the Economic and Energetic Potential of Residues from the Green Coconut Industry
}

\author{
Débora C. F. Romão, ${ }^{\odot *, a}$ Claudio C. Santana Jr., ${ }^{a}$ Mateus R. Brito, ${ }^{a}$ Elisandra Scapin, ${ }^{\odot a}$ \\ Marcelo Pedroza, ${ }^{\circledR b}$ Michele C. D. Rambo ${ }^{\circledR b}$ and Magale K. D. Rambo ${ }^{\circledR a}$ \\ aPrograma de Pós-Graduação em Ciências do Ambiente, Universidade Federal do Tocantins (UFT), \\ Campus de Palmas, 77001-090 Palmas-TO, Brazil \\ ${ }^{b}$ Instituto Federal de Educação, Ciência e Tecnologia do Tocantins, Campus de Palmas, \\ 77020-450 Palmas-TO, Brazil
}

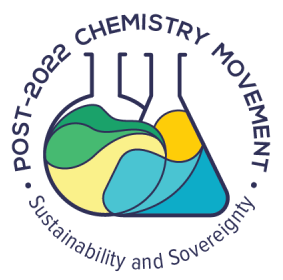

This work uses new waste feedstock, essential to increase the range of new biomasses, demonstrating experimentally and numerically the economic potential of coconut husk residues to produce renewable biofuels (pyrolytic oil and biochar) through slow pyrolysis. The samples were submitted to a pyrolysis process $\left(500^{\circ} \mathrm{C}\right.$ for $30 \mathrm{~min}$, with a heating rate of $20^{\circ} \mathrm{C} \mathrm{min}^{-1}$, using water vapor as carrier gas), where the biochar and bio-oil yields reached were 31 and 30\%, respectively. The main components found in bio-oil were furfural (29.23\%), phenol (22.18\%), and isoeugenol $(10.26 \%)$. The surface area values (Brunauer-Emmett-Teller (BET) and Langmuir) found for biochar were greater than $300 \mathrm{~m}^{2} \mathrm{~g}^{-1}$ and a micropore volume of $0.11 \mathrm{~cm}^{3} \mathrm{~g}^{-1}$. The estimated theoretical energy potential of biochar and bio-oil were 208,107,180 MJ and 190,205,438 MJ, equivalent to 3,729,518.4 tons of coconut husks. Thus, this study brings as a novelty a new feedstock associated with bioprocess technological models that will pave sustainable avenues for the development of biorefineries, offering a sustainable green option to produce bioproducts and bioenergy. In the proposed model, the wastes are valorized using various processes addressing economy.

Keywords: lignocellulosic biomass, pyrolysis, bio-oil, biochar, energy

\section{Introduction}

There is a growing search for renewable energy resources that can replace the existing global dependence on fossilbased resources. ${ }^{1}$ Among these renewable resources, one can find lignocellulosic biomass, considered attractive in energy utilization, because besides its great abundance, low cost, and carbon-neutral nature, it has the potential to be transformed into biofuels through various technologies. ${ }^{2,3}$ Residues from agricultural activities and the forest environment are important sources of lignocellulosic biomass. ${ }^{4}$

However, studies have projected that 476 million tons of lignocellulosic biomass will be required to meet the growing market for bio-based products by 2030. To meet these needs, the wide-scale utilization of non-traditional waste biomass sources will be adopted by biorefineries. ${ }^{5}$ Between these underutilised crops,

*e-mail: deboraromao.eng@gmail.com

Editor handled this article: Teodoro S. Kaufman the coconut husks (Cocos nucifera L.) are promising. According to Santana Jr. et al., ${ }^{6}$ they are a drought tolerant crop, and due to their chemical composition, $30 \%$ cellulose, $27 \%$ hemicellulose, and $27 \%$ lignin, they have potential for industrial utilization.

Brazil is one of the largest coconut producers in the world and, therefore, generates a large amount of residues from this market. For every $250 \mathrm{~mL}$ of coconut water (the main part sold), about $1 \mathrm{~kg}$ of waste material is generated. In 2019, Brazil produced approximately 1.5 million tons of this waste, which becomes an environmental liability due to the huge space it occupies in landfills and its slow degradation ( 8 years on average) ${ }^{7}$

This biomass can be converted into value-added products such as biochar, bio-oil, and non-condensable gas from the pyrolysis process, which is a technique considered promising in the context of energy supply and carbon emissions control. ${ }^{2}$

Bio-oil contains various organic compounds, such as acids, phenols, ketones, esters, alcohols, aldehydes, sugars, 
and ethers. Thus, due to its characteristics, bio-oil has the potential to be used as a raw material in the chemical industry and also as fuel for engines, boilers, and turbines, thus being an alternative to fossil fuels. ${ }^{3}$

Biochar has several applications, and can be used to correct soil, improving its structure and fertility, nutrient availability, water retention capacity, and also for carbon sequestration. Other applications include its use as an adsorption material to remove pollutants, and also in the chemical and pharmaceutical industries., ${ }^{4,5}$ Among its environmental applications, biochar has also been used for wastewater treatment, soil remediation, ${ }^{8}$ and capturing pollutant gases, since it has a good adsorption capacity. ${ }^{9}$ It can also be used as a fuel for thermal and electrical energy generation. ${ }^{10,11}$

In order to evaluate the potential of the coconut products mentioned above, the objective of this study was the investigation of the economic and energy costs, including a close value of the bioproducts, thus confirming the novelty of the present work with one global analysis.

Therefore, the use of these residues becomes an interesting opportunity to produce new marketable compounds, especially for the chemical industry, in addition to minimizing the adverse environmental impacts caused by their disposal.

\section{Experimental}

\section{Sample preparation}

The green coconut epicarp (Cocos nucifera L.) was collected from the coconut residues discarded in the trade of the city of Palmas, in the state of Tocantins. The collected material was processed at the Chemistry Laboratory of the Federal University of Tocantins, where the fractions were separated manually, the husks were dried in an oven at $50{ }^{\circ} \mathrm{C}$ for $24 \mathrm{~h}$, ground (48 mesh) in a Willye knife mill (model Star FT 50, Fortenox, Piracicaba, São Paulo, Brazil), and deposited in hermetically sealed glass bottles. All analyzes were performed in duplicates.

\section{Proximate chemical analysis}

The proximate chemical analysis was carried out following the procedures of the American Society for Tests and Materials (ASTM). The raw biomass was taken to the greenhouse, remaining for $12 \mathrm{~h}$ at $105{ }^{\circ} \mathrm{C}$ to determine the moisture. ${ }^{12}$ Then, this material was kept for $4 \mathrm{~h}$ at a temperature of $600{ }^{\circ} \mathrm{C}$ to determine the ash content. ${ }^{13}$ The volatile matter was measured with the aid of the muffle at $800 \pm 10{ }^{\circ} \mathrm{C}$ for $8 \mathrm{~min}$, based on a dry sample of $1.0 \mathrm{~g} .{ }^{14}$
Through the difference between the ash content and volatile matter, the percentage of fixed carbon (FC) was determined.

\section{Soxhlet extraction}

A Soxhlet extractor was used, and extraction cartridges received $3 \mathrm{~g}$ of each biomass. After that, they were covered with cotton wool and then taken to the extractor, with $190 \mathrm{~mL}$ of $90 \%$ ethanol (Merck, Darmstadt, Germany) for $12 \mathrm{~h}$ in reflux (NREL/TP-510-42619). ${ }^{15}$ After the end of the reflux, the cartridges were taken and placed on Petri dishes on the counter for $48 \mathrm{~h}$ to be dried. After $48 \mathrm{~h}$, the moisture content of the extracted sample was determined again, so that the extractive content was calculated according to the weight loss after extraction, deducting the moisture.

\section{Acid hydrolysis}

The acid hydrolysis step was performed according to the methodology of the National Renewable Energy Laboratory ${ }^{16}$ for the determination of structural carbohydrates and lignin in biomass. Pressure tubes were used, in which $300 \mathrm{mg}$ of the extracted biomass were placed, and $3.0 \mathrm{~mL}$ (4.91 g) of $\mathrm{H}_{2} \mathrm{SO}_{4}$ (Merck, Darmstadt, Germany) at $72 \%(\mathrm{~m} / \mathrm{m})$; then, the tubes were taken to a water bath (TE 056, Technal, Piracicaba, Brazil) for $120 \mathrm{~min}$ at $60{ }^{\circ} \mathrm{C}$ and shaken every $10 \mathrm{~min}$. This is the primary hydrolysis step. Subsequently, $84 \mathrm{~mL}$ of deionized water was added so that the concentration of sulfuric acid was reduced to $4 \%(\mathrm{~m} / \mathrm{m})$; the tubes were then taken to an autoclave (AV 18, Phoenix, Araraquara, Brazil) for $1 \mathrm{~h}$ at $120^{\circ} \mathrm{C}$ (secondary hydrolysis step).

After this step, the hydrolyzed solution was filtered in crucibles of medium porosity (10 to $15 \mu \mathrm{m})$ using a vacuum pump (NOF-650, Evpvacuum, Shanghai, China). The solids retained in the filter crucibles were taken to an oven at $105^{\circ} \mathrm{C}$ so that the content of acid-insoluble residue (AIR) was determined, and then kept in a muffle furnace for $4 \mathrm{~h}$ at $575{ }^{\circ} \mathrm{C}$ to obtain the acid-insoluble ash (AIA). From the difference between AIR and AIA, the content of insoluble lignin-also known as Klason lignin (KL)-was determined. The filtrate (hydrolysate) contains the acidsoluble lignin (ASL) and any other soluble acid components of the biomass, such as the hydrolyzed sugars.

\section{Cellulose, hemicellulose and lignin analysis}

According to Association of Official Analytical Chemists, ${ }^{17}$ the acid detergent fiber (ADF) and cold neutral detergent (FDN) were used to determine hemicellulose content, while lignin was determined by NREL methodologies, and cellulose by difference. ${ }^{18}$ 


\section{Pyrolysis process}

Pyrolysis occurred using a tubular fixed-bed quartz reactor, $10 \mathrm{~cm}$ in external diameter and $100 \mathrm{~cm}$ in length, using $30 \mathrm{~g}$ of biomass at $500{ }^{\circ} \mathrm{C}$ with a heating rate of $20{ }^{\circ} \mathrm{C}$ for 30 min inserted into the reactor in batch mode. ${ }^{19}$ Water vapor was used as carrier gas. At the end of the reactor, a condensing system composed of a Friedrich-type condenser, a vacuum flask, two tubes, and a $20 \mathrm{~L}$ water tank for cooling the condenser was coupled. With the passage of the vapor, it was possible to separate the biogas from the liquid products (bio-oil and acid extract), which are retained in the vacuum flask. For the bio-oil and acid extract separation, dichloromethane (Merck, Darmstadt, Germany) $(20 \mathrm{~mL})$ was used. After the pyrolysis process, biochar and bio-oil were collected and weighed to obtain product yields. Syngas yield was calculated by difference. The biochar and bio-oil yields (\%) were calculated according to equations 1 and 2 , respectively.

Biochar yield $(\%)=\frac{\mathrm{m} 2}{\mathrm{~m} 1} \times 100$

where $\mathrm{m} 1$ is weight of sample in grams $(\mathrm{g})$ and $\mathrm{m} 2$ weight of char in grams $(\mathrm{g})$.

Bio-oil yield $(\%)=\frac{\mathrm{m} 2}{\mathrm{~m} 1} \times 100$

where $\mathrm{m} 1$ is weight of sample in grams $(\mathrm{g})$ and $\mathrm{m}_{2}$ weight of bio-oil in grams $(\mathrm{g})$.

\section{Biochar analysis}

\section{Biochar activation}

Biochar activation was carried out with a solution of zinc chloride- $\mathrm{ZnCl}_{2}$ from Merck (Darmstadt, Germany) with a concentration of $10 \% \mathrm{~m} / \mathrm{v}$ in the proportion of 1:5 (biochar:solution, mass:volume) that was added to biochar (fraction from the pyrolysis process). Then, the sample container was covered with film paper for $24 \mathrm{~h}$. Subsequently, the sample was washed with distilled water and kiln-dried at $110 \pm 5^{\circ} \mathrm{C} .{ }^{20}$

The washed biomass was placed in a cordierite crucible, closed with rock wool and cordierite plate, and once again it was pyrolyzed in a vertical oven (Jung 815) at $600 \pm 5^{\circ} \mathrm{C}$ for $2 \mathrm{~h}$. A $2 \mathrm{~mol} \mathrm{~L}^{-1}$ solution of hydrochloric acid- $\mathrm{HCl}$ (Merck, Darmstadt, Germany) was used to wash the activated carbon, removing and unclogging the pores. The process was concluded with drying the sample in an oven at $110 \pm$ $5{ }^{\circ} \mathrm{C}$ for $24 \mathrm{~h}$, resulting in the coconut husk activated carbon.

\section{Surface area analysis}

The BET (Brunauer-Emmett-Teller) analysis was carried out to determine the surface area and porosity of the biochar. BET analysis was executed using a Micromeritics ASAP 2010 (Norcross, GA 30093 USA). The sample is previously treated under vacuum in order to clean the surface and is then sent for analysis. For each run, $0.5 \mathrm{~g}$ of sample was used and the samples were degassed at $300{ }^{\circ} \mathrm{C}$ for $2 \mathrm{~h}$ under nitrogen in $77 \mathrm{~K}$ of temperature. The diameter range used as standard was from 0.35 to $300 \mathrm{~nm}$ for the pores and from 0.01 to $3.000 \mathrm{~m}^{2} \mathrm{~g}^{-1}$ in the surface area range. The partial pressures used are between 0.01 and 0.995 . For area calculation, both BET and Langmuir, the range used is from 0.05 to 0.30 . For total pore volume, the last point, 0.995 , is used. The partial pressures used were from 0.02 to 0.995 in adsorption and desorption.

\section{Energy yield}

The energy yield was calculated by the following equation $3:^{21}$

Energy yield $(\%)=\frac{\mathrm{Wb}}{\mathrm{Wrb}} \times 100 \times \frac{\mathrm{HHVb}}{\mathrm{HHVrb}}$

where $\mathrm{Wb}=$ weight of biochar $(\mathrm{kg})$; Wrb = weight of raw biomass $(\mathrm{kg})$; $\mathrm{HHVb}=$ higher heating value of biochar $\left(\mathrm{MJ} \mathrm{kg}^{-1}\right.$ ) (it is considered to be $24.15 \mathrm{MJ} \mathrm{kg}^{-1}$ );22 $\mathrm{HHVrb}=$ higher heating value of raw biomass $\left(\mathrm{MJ} \mathrm{kg}^{-1}\right)$ (it is considered to be $18.71 \mathrm{MJ} \mathrm{kg}^{-1}$ ). ${ }^{23}$

\section{Bio-oil analysis}

\section{Analysis by gas chromatography mass spectrometry (GC-MS)}

With the aid of GC-MS QP2010 Plus equipment (PerkinElmer do Brasil Ltda, São Paulo, Brazil) equipped with a capillary column Rtx-5MS WCOT $(30 \mathrm{~m} \times 0.25 \mathrm{~mm} \times 0.25 \mu \mathrm{m})$, the organic and aqueous bio-oil fraction were separated. For the chromatographic separation, the planning for the use of temperatures was followed: for $1 \mathrm{~min}$ (isothermal), raised to $7{ }^{\circ} \mathrm{C} \mathrm{min}{ }^{-1}$ at $100{ }^{\circ} \mathrm{C}$ and then at $4{ }^{\circ} \mathrm{C} \mathrm{min}-1$ at $320^{\circ} \mathrm{C}$ followed by $10 \mathrm{~min}$ at $320^{\circ} \mathrm{C}$. The carrier gas used was helium at $1.90 \mathrm{~mL} \mathrm{~min}^{-1}$. To obtain the mass spectra, the IEI mode (with ionization energy of $70 \mathrm{eV}$ ) was used. The quantification of the components was carried out by the peak area.

\section{Economic and energetic potential estimate}

A survey of the economic profitability was carried out from the main products found in bio-oil and biochar. 
The amount obtained of each product from the processing of 1 ton of coconut biomass was considered, taking into account the respective yields, along with the market values $^{24,25}$ obtained by Sigma-Aldrich for the bio-oil products and by the SEFA Ordinance No. 611, dated 09/10/2015, ${ }^{25}$ of the State of Pará for the biochar, in order to obtain a value close to how much the sale of these products would yield. Expenditure on electrical energy, equipment, and water were not considered.

Considering the possibility of performing the energy utilization of coconut husks, the theoretical energy potential of biochar and bio-oil was also estimated using equation 4 , according to Milian-Luperón et al.:26

$\mathrm{TEP}=\frac{\mathrm{BWY} \times \mathrm{AEV}}{100}$

where TEP $=$ theoretical energy potential $(\mathrm{MJ})$; $\mathrm{BWY}=$ biomass waste yield $(\mathrm{kg}) ; \mathrm{AEV}=$ average energy value $\left(\mathrm{MJ} \mathrm{kg}^{-1}\right.$ ) (it is considered to be ca. $18 \mathrm{MJ} \mathrm{kg}^{-1}$ when using biochar and ca. $17 \mathrm{MJ} \mathrm{kg}^{-1}$ for bio-oil).

\section{Results and Discussion}

\section{Physical-chemical characterization}

Figure 1 shows the values obtained in the proximate and immediate analysis of the crude biomasses.

The ash $(3.60 \%)$ and moisture values found were low, similar to other studies that used pyrolysis on lignocellulosic biomass, according to Rambo et al. ${ }^{27}$ who obtained $1.41 \%$ ash and $9.56 \%$ moisture for coconut residues. Ali et al. ${ }^{28}$ found the same amount of ash (3.6\%) and moisture in coconut husk residues (7.9\%). High ash content can impair acid and/or enzymatic hydrolysis processes. ${ }^{23}$ Accordingly, a low ash value is important when considering the processes involved in the utilization of lignocellulosic biomass.
The moisture content found (6.1\%) by Balasundram et al. ${ }^{29}$ for coconut residues was similar to this study. Moisture content below $10 \%$ is considered favorable because it can increase the energy content of the biomass, ${ }^{29}$ although the comparison of moisture values is too relative, since it strongly depends on the biomass conditions/origin.

Romão et al. ${ }^{30}$ obtained a total lignin amount of approximately $30 \%$ under similar hydrolysis conditions, which resulted in similar data for green coconut mesocarp. Scapin et al. ${ }^{31}$ obtained for the pequi (Caryocar brasiliense) biomass a total lignin (TL) content of $25.71 \%$, a value similar to that found in this study $(26.04 \%)$. High contents of sugars were obtained, considering cellulose (48.85\%) and hemicellulose $(16.19 \%)$, which together add up to $65.04 \%$, as well as Santana Jr., ${ }^{22}$ who obtained $>85 \%$ for coconut mesocarp, indicating that the utilization of this biomass is favorable for the use in biorefineries. ${ }^{31}$

The extractive value was below $10 \%(8.92 \%)$, which is the expected range for lignocellulosic biomasses. ${ }^{32}$ Wang et al..$^{33}$ obtained $4.97 \%$ for bamboo biomass and Yu et al. ${ }^{34}$ obtained $5.7 \%$ for pine. Extractives can inhibit gas and char formation. ${ }^{35}$ Thus, obtaining low values becomes interesting; moreover, it prevents parallel reactions from occurring, which may affect the selectivity of the process. ${ }^{36}$

\section{Pyrolysis products}

\section{Biochar and bio-oil}

The biochar yield found was $31 \%$, a similar result found for other lignocellulosic biomasses submitted to pyrolysis in the temperature range of $400-700{ }^{\circ} \mathrm{C}$, even under different residence times, according to the studies contained in Table 1.

Mohammed et al. ${ }^{37}$ using napier grass, compared the bio-oil and biochar obtained from different approaches: pyrolysis from raw biomass and pyrolysis for the catalytic process. The biochar recorded from the raw biomass was

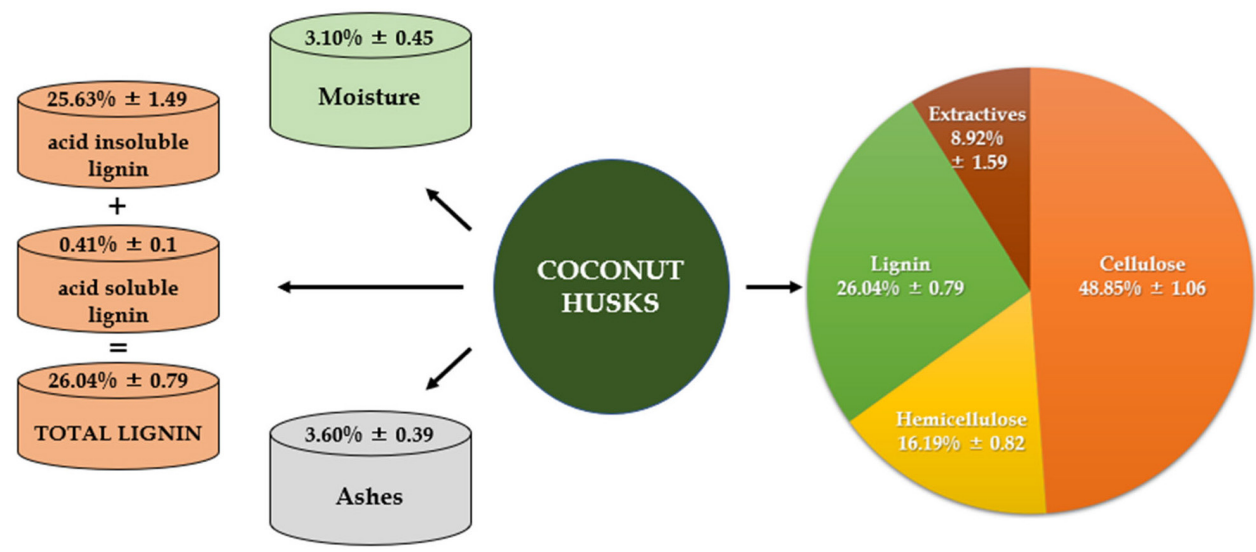

Figure 1. Composition of lignocellulosic biomass. 
Table 1. Yield of the biochar of lignocellulosic biomass residues

\begin{tabular}{|c|c|c|c|c|}
\hline Biomass & Temperature $/{ }^{\circ} \mathrm{C}$ & Residence time / min & Yield / wt. \% & Reference \\
\hline Coconut pith & 500 & 60 & 36.16 & 38 \\
\hline Coconut shell & 500 & 20 & 38.30 & 39 \\
\hline Coconut shell & 700 & 5 & 29.22 & 7 \\
\hline Baru & 450 & 30 & $>48.00$ & 40 \\
\hline Pequi & 500 & 30 & 34.00 & 41 \\
\hline Rice husk & 450 & 60 & 35.00 & 42 \\
\hline Cotton by-products & 400 & 240 & 44.38 & 43 \\
\hline Pine nut shells & 550 & 20 & 34.11 & 44 \\
\hline Sawdust & 500 & 50 & 38.60 & 45 \\
\hline
\end{tabular}

$29.24 \%$. For the catalytic process, the biochar has a small increment (29.79-30.22 wt.\%). This demonstrates that the biochar obtained in the present work had better yields (31\%) and without additional steps.

The presence of some minerals, a high lignin content, and a high pyrolysis temperature range $\left(400-700{ }^{\circ} \mathrm{C}\right)$ are conditions that favor the production of a stable biochar with high porosity and a strongly developed specific surface area. ${ }^{9,46,47}$

Table 2 shows satisfactory results regarding the surface area and micropore of the coconut husks. A high surface area associated with high porosity are important physical properties of biochar because they directly influence many of its applications, such as the absorption capacity ${ }^{48}$ which are similar to commercial activated vegetable carbon that is widely used as an adsorbent.

Table 2. Surface area and porosity of the biochar from coconut husks

\begin{tabular}{lcc}
\hline \multirow{2}{*}{ Component } & \multicolumn{2}{c}{ Biochar } \\
\cline { 2 - 3 } & AGCB & CVAC \\
\hline Surface area BET / $\left(\mathrm{m}^{2} \mathrm{~g}^{-1}\right)$ & $321.4532 \pm 6.5400$ & 597.33 \\
Surface area Langmuir $/\left(\mathrm{m}^{2} \mathrm{~g}^{-1}\right)$ & $432.3222 \pm 1.6591$ & - \\
External surface area $/\left(\mathrm{m}^{2} \mathrm{~g}^{-1}\right)$ & 73.4686 & - \\
Total pore volume / $\left(\mathrm{cm}^{3} \mathrm{~g}^{-1}\right)$ & 0.164346 & - \\
Micropore volume / $\left(\mathrm{cm}^{3} \mathrm{~g}^{-1}\right)$ & 0.115292 & 0.22 \\
Micropore area / $\left(\mathrm{m}^{2} \mathrm{~g}^{-1}\right)$ & 247.9846 & - \\
Average pore size / $\AA$ & 20.3378 & - \\
\hline AGCB: activad &
\end{tabular}

AGCB: activated green coconut biochar; CVAC: commercial activated vegetable carbon. ${ }^{49} \mathrm{BET}$ : Brunauer-Emmett-Teller.

The surface area (BET and Langmuir) of biochar was found to be above $300 \mathrm{~m}^{2} \mathrm{~g}^{-1}$. Comparing with already published works, Wang et al. ${ }^{33}$ obtained a surface area of $181.05 \mathrm{~m}^{2} \mathrm{~g}^{-1}$ for bamboo biochar, and Brito et al.$^{41}$ found $30.1 \mathrm{~m}^{2} \mathrm{~g}^{-1}$ (BET) and $30.9 \mathrm{~m}^{2} \mathrm{~g}^{-1}$ (Langmuir) for activated pequi biochar, using the same activation process. According to the guidelines for the certification of biochar (European
Biochar Certificate, version 4.8), ${ }^{50}$ a minimum specific surface $>150 \mathrm{~m}^{2} \mathrm{~g}^{-1}$ is required. Thus, the value $>300 \mathrm{~m}^{2} \mathrm{~g}^{-1}$ shows the huge potential of this biochar to be used as adsorbent in the soil, since a high surface area favors its application in the stabilization/immobilization of heavy metals, and it can also be used in the removal of heavy metals from wastewater for reducing threats to human health. ${ }^{51}$ Biochar with large surface area applied to the soil can also adsorb greenhouse gases, such as nitrous oxide $\left(\mathrm{N}_{2} \mathrm{O}\right)$, reducing their emission to the atmosphere. ${ }^{48}$

The micropore volume $\left(0.115292 \mathrm{~cm}^{3} \mathrm{~g}^{-1}\right)$ of the coconut husks biochar was satisfactory and higher than that found in biochars of other biomasses. ${ }^{48}$ Micropores in biochar are responsible for the high absorption capacity and surface area. The presence of a good microporosity provides advantages to the soil, such as the sorption of dissolved organic matter and a better activity of microorganisms, which accelerates the remediation of organic pollutants in the soils. ${ }^{48}$ The characteristics of the biochar from coconut husks also demonstrate its feasibility for application in civil construction, because, to be used as a cementitious admixtures, biochar needs to have a surface area greater than $5 \mathrm{~m}^{2} \mathrm{~g}^{-1}$ and a micropore volume greater than $0.010 \mathrm{~cm}^{3} \mathrm{~g}^{-1}$, and values higher than these were found. ${ }^{51}$ From the pore diameter distribution, it can be observed that pores are smaller than $20.50 \AA$, confirming that the AGCB structure is constituted, for the most part, by micropores.

The calculated energy yield (equation 3 ) for coconut husks was $40.01 \%$ (Table 3), which was similar to that found by Padilla et al. ${ }^{52}$ whose energy yield was $52.76 \%$ for the green coconut husks biochar also submitted to pyrolysis in the temperature of $500{ }^{\circ} \mathrm{C}$. Another study carried out by Selvarajoo and Oochit ${ }^{21}$ with palm fiber obtained an energy yield of $47.93 \%$ for biochar pyrolyzed at $500{ }^{\circ} \mathrm{C}$. In both studies, the biomasses were subjected to different temperatures and it was concluded that the best energy yields of biochar were obtained at lower temperatures, 
indicating that a lower energy consumption can be used to produce the biochar to be used for this purpose.

Table 3. Higher heating value (HHV) for raw and biochar samples of coconut

\begin{tabular}{lcc}
\hline Sample & $\mathrm{HHV} /\left(\mathrm{MJ} \mathrm{kg}^{-1}\right)$ & Energy yield / \% \\
\hline Raw biomass & $18.71^{23}$ & - \\
$\mathrm{BCH}$ & $24.15^{22}$ & 40.01 \\
\hline
\end{tabular}

$\mathrm{BCH}$ : biochar of coconut husks.

Regarding bio-oil with $30 \%$ yield, the main compounds identified are water, acids, alcohols, aldehydes, esters, ketones, carbohydrates, hydrocarbons, phenols, and other lignin-derived and cellulose-derived substances ${ }^{7}$ (Figure 2). It was found phenol $(45.81 \%)$ and aldehyde $(32.76 \%)$ values in the composition of bio-oil, and lower ketone (11.7\%), alkene (5.24\%), alcohol (1.88\%), acid (1.7\%), and hydrocarbon $(0.91 \%)$ values. Similar results were found by Almeida et al. ${ }^{7}$ for coconut biomass, where it obtained $55.2 \%$ phenols, $14.2 \%$ aldehydes, $10.2 \%$ ketones, and $4.1 \%$ alcohols.

Mohammed et al..$^{53}$ studied the pyrolysis of bambara groundnut shell. The distribution of the chemical compound in the organic phase of the bio-oil presents a relationship with the pyrolysis temperature. The total phenolic content in the organic phase recorded at $450{ }^{\circ} \mathrm{C}$ was $74.08 \%$ and it increased to $82.28 \%$ at $750{ }^{\circ} \mathrm{C}$, suggesting that higher pyrolysis temperature promotes release of phenols from the lignin component of the biomass. This occurs because that primary degradation $\left(450-550{ }^{\circ} \mathrm{C}\right)$ of lignin generates maximum phenolics such as syringols and guaiacols while the secondary lignin decomposition promotes phenol. This observation is in good agreement with the report in this study (Table 4) for the primary degradation.

The high composition of acid, aldehydes, and ketones (> $40 \%$ ) in the organic phase could be attributed to the
Table 4. Chemical compounds of coconut husks bio-oil determined by GC-MS analysis

\begin{tabular}{lc}
\hline Compound & Height / \% \\
\hline Furfural & 29.23 \\
Phenol & 22.18 \\
Phenol, 2-methoxy- & 10.26 \\
p-Cresol & 4.52 \\
Phenol, 2-methyl- & 4.00 \\
2-Furancarboxaldehyde, 5-methyl- & 3.53 \\
2,4-Dimethylhept-1-ene & 3.24 \\
2-Propanone, 1-(acetyloxy)- & 3.18 \\
Creosol & 3.08 \\
2-Cyclopenten-1-one, 2-methyl- & 2.42 \\
Ethanone, 1-(2-furanyl)- & 2.13 \\
Cyclopentanone & 2.06 \\
2-Furanmethanol, tetrahydro- & 1.88 \\
Phenol, 4-ethyl-2-methoxy- & 1.77 \\
Acetic acid, trifluoro-, 3,7-dimethyloctyl ester & 1.70 \\
2-Cyclopenten-1-one, 2,3-dimethyl- & 1.33 \\
1-Undecene, 7-methyl- & 1.19 \\
Nonane, 2,6-dimethyl- & 0.91 \\
1-Undecene, 7-methyl- & 0.81 \\
2-Cyclopenten-1-one, 3,4-dimethyl- & 0.58 \\
\hline
\end{tabular}

polymerization of active shortchain organic molecules generated from methyl esters and other longchain molecules with the unstable carbonyls and carboxylics during pyrolysis vapour condensation..$^{53}$

Mohammed et al..$^{54}$ evaluated the changes in the composition between the raw pyrolytic oil and the upgraded pyrolytic oil. Increase in phenol content was recorded in upgraded pyrolytic oil relative to the raw pyrolytic oil. However, the bio-oil produced in this study (raw) shows the same phenol composition (45.8\%) compared with the upgraded oil (41-47\%) produced with catalysts. Another similarity is about the composition of aromatic hydrocarbon

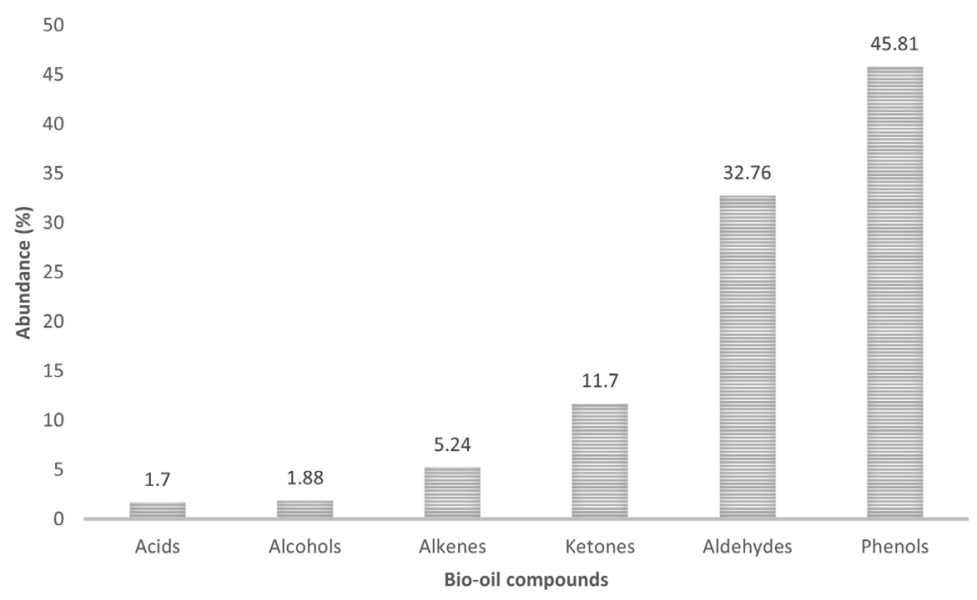

Figure 2. Chemical composition of bio-oil from coconut husks. 
in the present oil compared with the upgraded oil obtained by the authors ${ }^{54}$ both show low composition. This suggests that the oil produced by the authors has enormous potential for use if it is upgraded in the future with catalysts.

The most abundant components found in the bio-oil (Table 4) from coconut husks were furfural (29.23\%), phenol (22.18\%), and phenol, 2-methoxy- (isoeugenol) $(10.26 \%)$. Currently, the main raw material for furfural production used in the industry comes from lignocellulosic biomass, and this compound is produced mainly by the degradation of hemicellulose. Furfural can be used as a sustainable substitute for petroleum-based components in the production of fine chemicals and plastics, as a solvent for the refining of lubricant oil and diesel fuel, as well as in the production of agrochemicals. ${ }^{55-57}$

Phenolic compounds have many applications in the pharmaceutical industry, in the production of biomaterials and in the food industry because they have antioxidant and antimicrobial effects that help prevent the oxidation and spoilage of foods. ${ }^{58,59}$ Phenol is also a chemical product used as a building block in synthetic fibers, engineering plastics, and phenolic resins. ${ }^{60,61}$

\section{Proximate economic and energetic analysis}

The three products found in larger amounts in the bio-oil were considered, and together comprise $>60 \%$ of its composition by mass, which are furfural, phenol, and isoeugenol. An average yield of $30 \%$ bio-oil was considered, as it is expected for lignocellulosic biomass under similar conditions of pyrolysis temperature and time. ${ }^{40,41}$ As the biochar yield found was $31 \%, 310 \mathrm{~kg}$ of biochar can be obtained per ton of coconut husks.

After admitting the market values ${ }^{24,25}$ of each product (Table 5), it is possible to obtain a total balance of US\$ $81,017.48$ from the processing of 1 ton of biomass with the sale of the main products in the green coconut biomass, disregarding the processing expenses, such as water and energy. Only the dichloromethane, reagent used for the bioprodutcs separation, was considered.

Therefore, these chemical compounds found in biooil can be separated and purified by different processing methods to be used as fine chemicals in different applications in chemical industries. ${ }^{45}$ The present study did not evaluated the purity of these compouns, only the identification/quantification of the potenital products. Future works intend to make this separation.

Biochar is a marketable bioproduct, with applicability in agriculture, industry, and the energy sector. The quality, safety, and quantity of the bioproduct have a significant effect on bioeconomy; thus, these factors must be
Table 5. Market values ${ }^{24,25}$ of major bio-oil components and biochar from coconut husks

\begin{tabular}{lcc}
\hline Component & & Market values / $\left(\mathrm{US} \$ \mathrm{~kg}^{-1}\right)$ \\
\hline \multirow{3}{*}{ Bio-oil } & furfural & 119.00 \\
& phenol & 908.00 \\
& isoeugenol & 435.00 \\
\hline Biochar & & 0.25 \\
\hline
\end{tabular}

considered in the biochar production, as a large effective production will result in economic and environmental benefits. $^{48}$

Both biochar and bio-oil can be used as energy sources through combustion. Considering the processing of 1 ton of coconut husks biomass, based on calculations made of theoretical energy potential (TEP) (equation 4), with a yield of $30 \%$ for bio-oil and $31 \%$ for biochar, it is possible to estimate a TEP of $51 \mathrm{MJ}$ for bio-oil and 55.8 MJ for biochar for 1 ton of residues.

Thus, seeking to estimate what would be the TEP of coconut husk residues produced in Brazil, the production of $4,661,898$ tons of green coconut in Brazil in $2019^{62}$ and the percentage of the husk corresponding to proximately $80 \%$ of the fruit weight was taken as a basis. For the calculation (equation 4) 3,729,518.4 tons of coconut husks (80\%) were used, yields of 30 and $31 \%$ and the values obtained for TEP of 51 and 55.8 MJ for bio-oil and biochar, respectively. Therefore, the theoretical energy potential reached was approximately $190,205,438 \mathrm{MJ}$ or 5,283,484 MWh for bio-oil and 208,107,180 MJ or 5,780,755 MWh for biochar.

Using the same calculation base (equation 4), MilianLuperón et al. ${ }^{26}$ obtained an energy potential of 128,448 MJ for biochar and 113,940 MJ for bio-oil from 716 ton of coffee husks and also 20,160 and 22,860 MJ for biochar and bio-oil, respectively, of 121 ton of cocoa seed husks. Similarly, for 3.026 ton of residues from cupuaçu husks produced in Brazil, Marasca et al. ${ }^{63}$ obtained a TEP of 70,342 MJ. It was possible to reach high TEP values for green coconut husks as this fruit has a high production in Brazil, generating large amounts of residues that can be used as an energy source.

The total TEP of the sum of the biochar and biooil potentials from the green coconut husks found in equation $4^{26}$ was $398,312,618 \mathrm{MJ}$ for one year of residue production in Brazil. If this amount of energy were used to supply the energy demand of Brazilian homes, whose average consumption per home is approximately $0.1608 \mathrm{MWh}$ month $^{-1},{ }^{64}$ this amount of biochar and biooil produced would be able to supply the consumption of 5,734,747 homes in a 12-month period. This is a gross consideration, disregarding expenses such as the industrial 


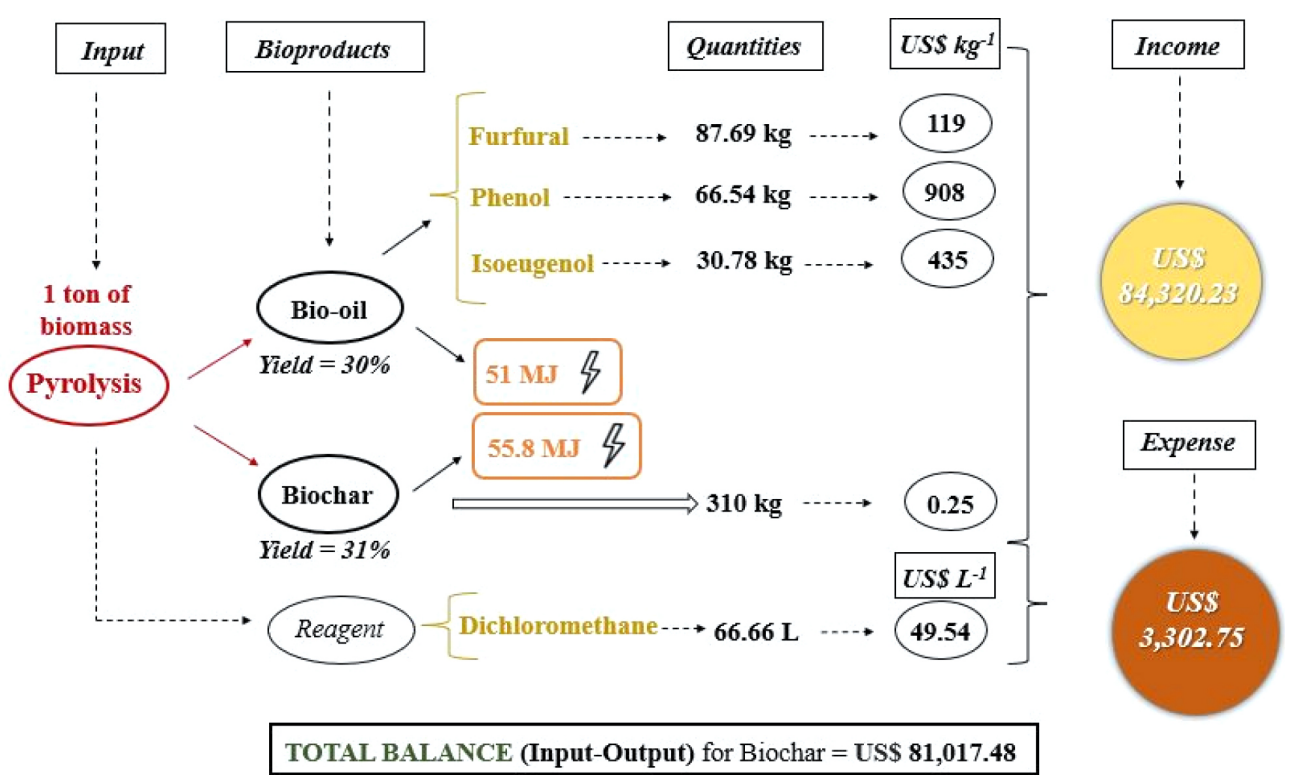

Figure 3. Product income and theoretical energy potential obtained from biomass pyrolysis.

scale conversion of biomass into biochar and bio-oil and of these into energy, logistics, equipment maintenance, employees, among others.

Figure 3 shows a survey of the economic profitability and theoretical energy potential from the main products found in bio-oil and biochar from the pyrolysis of green coconut husks.

Biochar production can be attractive if the income obtained offsets the economic costs of all biomass processing, achieving an economic balance. Commercialization of biochar seems promising when used in soil agriculture to improve soil characteristics and as a greenhouse gas adsorber for carbon dioxide sequestration payments. ${ }^{48}$

The feasibility of co-production of biochar and methanol (biofuel) from the heat treatment of pine biomass was studied by Shabangu et al. ${ }^{65}$ The variables that had the greatest impact on the profitability of the system were the cost of biomass, the value of the products (methanol and biochar) and the capital costs represented by the size of the plant and the total investment factor of the project. The sales prices found for the biochar that make the system viable were US\$220 $\mathrm{t}^{-1}$ for pyrolysis at $300{ }^{\circ} \mathrm{C}$ and US $\$ 280 \mathrm{t}^{-1}$ for pyrolysis at $450{ }^{\circ} \mathrm{C}$. It is also concluded that the production of biochar together with methanol is more advantageous as it helps to reduce biofuel costs, thus demonstrating the applicability and economic importance of biochar.

\section{Conclusions}

The results of the bio-oil collected revealed that the constituents are predominantly phenols, aldehydes, and ketones, with traces of acid, alkenes, and alcohols, important sources for production of quality biofuel and valuable chemicals. Among these compounds, furfural and phenol are present in more than $20 \%$ of the composition.

The produced biochar is also considered promising for use in adsorption processes, as a biofertilizer or solid fuel, because it has an excellent surface area $\left(>300 \mathrm{~m}^{2} \mathrm{~g}^{-1}\right)$ and micropore characteristics, in addition to its use for energy production, since it showed a satisfactory theoretical energy potential, and can be applied in combustion processes.

This study demonstrated that pyrolytic oil and biochar derived from coconut husks can be transformed into highgrade pyrolytic oil, and other value-added chemicals can be produced. This study revealed that coconut husks, a food crop residue, are a good material for sustainable bioenergy production, generating a theoretical energy potential equivalent to $398,312,618 \mathrm{MJ}$ per year.

It is possible to develop a circular economy based on the bio-oil and biochar from coconut husks, generating economic and environmental gains; however, some challenges need to be faced and some social, political, and scientific barriers need to be overcome.

Thus, actions are needed, such as: investing in research that considers the industrial scale of biomass processing, such as biorefineries, since research is carried out in smallscale laboratories; knowing the long-term environmental impacts of the use of these bioproducts; ensuring incentives for the insertion of bio-oil and biochar at competitive prices in the market; developing efficient separation technologies; and obtaining biomasses with ideal properties for their various applications. 


\section{Acknowledgments}

The authors are grateful to the Coordination for the Improvement of Higher Education Personnel for the scholarship granted (CAPES), the Pos-Graduate Program of enviromental sciences (PPGCiamb) for all financial support by the Edital No. 19/2021, the Federal University of Tocantins, and the Federal Institute of Science and Technology of Tocantins (IFTO) by the Edital No. 28/2021 $\mathrm{PAP} / \mathrm{PQ}$ for all the support and for allowing the use of the laboratories.

\section{Author Contributions}

Debora Cristina F. Romão was responsible for supervision, conceptualization, resources, data curation, validation, formal analysis, software, visualization, investigation, writing-original draft, review, and editing; Claudio C. Santana Junior for data curation, validation, investigation, review, and editing; Mateus R Brito for data curation, validation, investigation, review, and editing; Elisandra Scapin for supervision, resources, investigation, and formal analysis; Michele C. D. Rambo for supervision, data curation, validation, investigation, review, and editing; Marcelo M. Pedroza for supervision, investigation, formal analysis, review, and editing; Magale K. D. Rambo for supervision, resources, conceptualization, visualization, data curation, formal analysisl, methodology, writingoriginal draft, review, and editing.

\section{References}

1. Persson, H.; Yang, W.; Fuel 2019, 252, 200.

2. Ahmed, A.; Bakar, M. S. A.; Sukri, R. S.; Hussain, M.; Farooq, A.; Moogi, S.; Park, Y.; Energy Convers. Manage. 2020, 226, 113502 .

3. Setter, C.; Costa, K. L. S.; Oliveira, T. J. P.; Mendes, R. F.; Fuel Process. Technol. 2020, 210, 106561.

4. Rangabhashiyam, S.; Balasubramanian, P.; Ind. Crops Prod. 2019, 128, 405 .

5. Hickey, D. T.; Hayes, D. J.; Pembroke, J. T.; Ryan, M. P.; Leahy, J. J.; Energies 2021, 14, 6406.

6. Santana Jr., C. C.; Rambo, M. C. D.; Teófilo, R. F.; Cardoso, W. J.; Bertuol, D. A.; Rambo, M. K. D.; Waste Biomass Valorization 2021, 12, 6875 .

7. Almeida, T. M.; Bispo, M. D.; Cardoso, A. R. T.; Migliorini, M. V.; Schena, T.; Campos, M. C. V.; Machado, M. E.; López, J. A.; Krause,L.C.; Caramão,E. B.; J.Agric. FoodChem. 2013, 61, 6812.

8. Anae, J.; Ahmad, N.; Kumar, V.; Thakur, V. K.; Gutierrez, T.; Yang, X. J.; Cai, C.; Yang, Z.; Coulon, F.; Sci. Total Environ. 2021, 767, 144351

9. Leng, L.; Xiong, Q.; Yang, L.; Li, H.; Zhou, Y.; Zhang, W.; Jiang, S.; Li, H.; Huang, H.; Sci. Total Environ. 2021, 763, 144204.
10. Santos, S. T. O.; Vieira Jr., C. M.; Silva, A. N.; Nascimento Jr., A. F.; Drummond, A. R. F.; Silva, S. P. R.; Braz. J. Dev. 2020 , 6,48662

11. Das, S. K.; Ghosh, G. K.; Avasthe, R.; Environ. Technol. Innovation 2021, 21, 101306

12. ASTM D 3173-87: Standard Test Method for Moisture in the Analysis Sample of Coal and Coke, West Conshohocken, 2017.

13. ASTM D 3174-04: Standard Test Method for Ash in the Analysis Sample of Coal and Coke from Coal, West Conshohocken, 2020.

14. ASTMD3175-07: Standard Test Method for Volatile Matter in the Analysis Sample of Coal and Coke, West Conshohocken, 2020.

15. National Renewable Energy Laboratory (NREL); NREL/TP510-42619: Determination of Extractives in Biomass; Golden, Colorado, 2008.

16. National Renewable Energy Laboratory (NREL); NREL/TP510-42618: Determination of Structural Carbohydrates and Lignin in Biomass; https://www.nrel.gov/docs/gen/fy13/42618. pdf, Golden, Colorado, 2008.

17. Association of Official Analytical Chemists (AOAC); Methods of Analysis of the Association of official Analytical Chemists, $12^{\text {th }}$ ed.; Washington, D.C., USA, 1995.

18. Ding, T. Y.; Hii, S. L.; Ong, L.; Bioresources 2012, 7, 1540.

19. Rodrigues, M.; Arruda, M. G.; Pedroza, M.; Fagnani, H. M. C.; Jaconi, A.; Rambo, M. K. D.; Res. Soc. Dev. 2021, 10, 115.

20. Costa, P. D.; Furmanski, L. M.; Dominguini, L.; Rev. Virtual Quim. 2015, 7, 1272.

21. Selvarajoo, A.; Oochit, D.; Mater. Sci. Energy Technol. 2020 , 3,575 .

22. Santana Jr., C. C.; Int. J. Adv. Eng. Res. Sci 2020, 7, 324

23. Rambo, M. K. D.; Alexandre, G. P.; Rambo, M. C. D.; Alves, A. R.; Garcia, W. T.; Baruque, E.; Food Sci. Technol. 2015, 35, 605

24. Sigma-Aldrich; https://www.sigmaaldrich.com/BR/pt/search/ furfural ?focus $=$ products $\&$ page $=1 \&$ perpage $=30 \&$ sort $=$ relevance \& term $=$ furfural \& type=product; https://www sigmaaldrich.com/BR/pt/search/phenol?focus=products\&page $=1 \&$ perpage $=30 \&$ sort $=$ relevance $\&$ term $=$ phenol $\&$ type $=$ product; https://www.sigmaaldrich.com/BR/pt/search/ isoeugenol? focus $=$ products $\&$ page $=1 \&$ perpage $=30 \&$ sort $=$ relevance\&term=isoeugenol\&type=product, accessed in March 2022.

25. Secretaria de Estado da Fazenda do Pará (SEFA); Portaria SEFA No. 611/2015; Altera o Boletim de Preços Mínimos de Mercado, Constante da Portaria No. 354, de 14 de dezembro de 2005, os Produtos Conforme Especifica; available at https://www.legisweb. com.br/legislacao/?id=303283, accessed in March 2022 .

26. Milian-Luperón, L.; Hernández-Rodríguez, M.; FalcónHernández, J.; Otero-Calvis, A.; Rev. Colomb. Quim. 2020, 49, 23.

27. Rambo, M. K. D.; Ferreira, M. M. C.; Melo, P. M.; Santana Jr., C. C.; Bertuol, D. A.; Rambo, M. C. D.; Food Sci. Technol. 2020, 40,444 
28. Ali, I.; Bahaitham, H.; Naebulharam, R.; Bioresour. Technol. 2017, 235, 1.

29. Balasundram, V.; Ibrahim, N.; Kasmani, R. M.; Hamid, M. K. A.; Isha, R.; Hasbullah, H.; Ali, R. R.; J. Cleaner Prod. 2017, 167, 218.

30. Romão, D. C. F.; Santana Jr., C. C.; Brito, M. R.; Queiroz, A. O.; Silva, G. S.; Rambo, M. K. D.; Rambo, M. C. D.; Barbosa, L. N.; Int. J. Adv. Eng. Res. Sci. 2020, 7, 160.

31. Scapin, E.; Rambo, M. K. D.; Viana, G. C. C.; Borges, M. S.; Rambo, M. C. D.; Carneiro, C.; J. Braz. Chem. Soc. 2020, 31, 1383.

32. Dai, L.; Wang, Y.; Liu, Y.; He, C.; Ruan, R.; Yu, Z.; Jiang, L.; Zeng, Z.; Wu, Q.; Sci. Total Environ. 2020, 749, 142386.

33. Wang, H.; Wang, X.; Cui, Y.; Xue, Z.; Ba, Y.; Bioresour. Technol. 2018, 263, 444.

34. Yu, J.; Paterson, N.; Blamey, J.; Millan, M.; Fuel 2017, 191, 140.

35. Wang, Y.; Wu, L.; Wang, C.; Yu, J.; Yang, Z.; Bioresour. Technol. 2011, 102, 7190.

36. Rambo, M. K. D.; Almeida, K. J. C. R.; Rambo, M. C. D.; Baruque Filho, E. A.; RBPG 2017, 13, 807. DOI: https://doi. org/10.21713/2358-2332.2016.v13.953.

37. Mohammed, I. Y.; Kazi, F. K.; Yusup, S.; Alaba, P. A.; Sani, Y. M.; Abakr, Y. A.; Energies 2016, 9, 246.

38. Johari, K.; Saman, N.; Song, S. T.; Cheu, S. C.; Kong, H.; Mat, H.; Chemosphere 2016, 156, 56.

39. Siengchum, T.; Isenberg, M.; Chuang, S. S. C.; Fuel 2013, 105, 559.

40. Rambo, M. K. D.; Nemet, Y. K. S.; Santana Jr., C. C.; Pedroza, M. M.; Rambo, M. C. D.; Biomass Convers. Biorefin. 2020, 12, 1.

41. Brito, M. R.; Santana Jr., C. C.; Rambo, M. K. D.; Scapin, E.; Pedroza, M. M.; Rambo, M. C. D.; Barbosa, L. N.; Int. J. Adv. Eng. Res. Sci. 2020, 7, 251.

42. Biswas, B.; Pandey, N.; Bisht, Y.; Singh, R.; Kumar, J.; Bhaskar, T.; Bioresour. Technol. 2017, 237, 57.

43. Chen, J.; Liang, J.; Wu, S.; Bioresour. Technol. 2016, $218,402$.

44. Qin, L.; Wu, Y.; Hou, Z.; Jiang, E.; Bioresour. Technol. 2020, 313, 123682.

45. Soni, B.; Karmee, S. K.; Fuel 2020, 271, 117570.

46. Leng, L.; Huang, H.; Bioresour. Technol. 2018, 270, 627.

47. Tomczyk, A.; Sokołowska, Z.; Boguta, P.; Rev. Environ. Sci. Biotechnol. 2020, 19, 191.

48. Oni, B. A.; Oziegbe, O.; Olawole, O. O.; Ann. Agric. Sci. 2019, 64, 222.

49. Linhares, F. A.; Marcílio, N. R.; Melo, P. J.; Sci. Cum Ind. 2016, 4, DOI: http://dx.doi.org/10.18226/23185279.v4iss2p74.
50. Comparison of European Biochar Certificate Version 4. 8 and IBI Biochar Standards Version 2.0, 2014, available at https:// www.biochar-international.org/wp-content/uploads/2018/04/ IBI-EBC_comparison_Oct2014.pdf, accessed in March 2022.

51. Hu, Q.; Jung, J.; Chen, D.; Leong, K.; Song, S.; Li, F.; Mohan, B. C.; Yao, Z.; Prabhakar, A. K.; Lin, X. H.; Lim, E. Y.; Zhang, L.; Souradeep, G.; Ok, Y. S.; Kua, H. W.; Li, S. F. Y.; Tan, H. T. W.; Dai, Y.; Tong, Y. W.; Peng, Y.; Joseph, S.; Wang, C.-H.; Sci. Total Environ. 2021, 757, 143820.

52. Padilla, E. R. D.; Belini, G. B.; Nakashima, G. T.; Waldman, W. R.; Yamaji, F. M.; Rev. Virtual Quim. 2018, 10, 334.

53. Mohammed, I. Y.; Abakr, Y. A.; Hui, J. N. X.; Alaba, P. A.; Morris, K. I.; Ibrahim, M. D.; J. Cleaner Prod. 2017, 164, 1430.

54. Mohammed, I. Y.; Abakr, Y. A.; Yusup, S.; Alaba, P. A.; Morris, K. I.; Sani, Y. M.; Kazi, F. K.; J. Cleaner Prod. 2017, 162, 817.

55. Liu, L.; Chang, H.; Jameel, H.; Park, S.; Bioresour. Technol. 2018, 252, 165.

56. Bizzi, C. A.; Santos, D.; Sieben, T. C.; Motta, G. V.; Mello, P. A.; Flores, E. M. M.; Ultrason. Sonochem. 2019, 51, 332.

57. Hui, W.; Zhou, Y.; Dong, Y.; Cao, Z.; He, F.; Cai, M.; Tao, D.; Green Energy Environ. 2019, 4, 49.

58. Okumura, H.; Green Process. Technol. 2021, 27, 2452.

59. Xu, Q.; Yu, Z.; Zeng, W.; Food Res. Int. 2021, 148, 110593.

60. Gao, H.; Zong, Z.; Teng, D.; Li, J.; Wei, X.; Guo, Q.; Zhao, T.; Bai, H.; Kang, Y.; Fuel 2021, 288, 119681.

61. Liu, X.; Li, Y.; Xing, X.; Zhang, G.; Jing, X.; Polymer 2021, 229, 124022.

62. Instituto Brasileiro de Geografia e Estatística (IBGE); Produção Agrícola - Lavoura Permanente; https://cidades.ibge.gov.br/ brasil/pesquisa/15/0, accessed in March 2022.

63. Marasca, N.; Brito, M. R.; Rambo, M. C. D.; Pedrazzi, C.; Scapin, E.; Rambo, M. K. D.; Food Sci. Technol. 2022, 42, e48421.

64. Empresa de Pesquisa Energética (EPE); Anuário Estatístico de Energia Elétrica 2020; https://www.epe. gov.br/sites-pt/publicacoes-dados-abertos/publicacoes/ Publicacoes Arquivos/publicacao-160/topico-168/ Anu \% C3\% A 1 rio\%20Estat\%C3\%ADstico\%20de\% 20 Energia\%20E1\%C3\%A9trica\%202020.pdf, accessed in March 2022.

65. Shabangu, S.; Woolf, D.; Fisher, E. M.; Angenent, L. T.; Lehmann, J.; Fuel 2014, 117, 742.

Submitted: October 14, 2021

Published online: March 8, 2022 